\title{
Clinicopathologic features of incident and subsequent tumors in patients with multiple primary cutaneous melanomas
}

\author{
Rajmohan Murali, MBBS, MD, FRCPA ${ }^{1,2,3}$, Chris Goumas, MPH $^{4}$, Anne Kricker, $\mathrm{PhD}^{2,4}$, \\ Lynn From, MD, FRCPC ${ }^{5}$, Klaus J. Busam, MD ${ }^{6}$, Colin B. Begg, PhD ${ }^{7}$, Terence Dwyer, MD, \\ $\mathrm{MPH}^{8}$, Stephen B. Gruber, MD, PhD, MPH ${ }^{9}$, Peter A. Kanetsky, PhD, MPH ${ }^{10}$, Irene Orlow, \\ $\mathrm{PhD}^{7}$, Stefano Rosso, PhD ${ }^{11}$, Nancy E. Thomas, MD, PhD ${ }^{12}$, Marianne Berwick, PhD, \\ MPH $^{13}$, Richard A. Scolyer, MBBS, MD, FRCPA, FRCPath ${ }^{1,2,3}$, and Bruce K. Armstrong, AM, \\ DPhil, FRACP, FAFPHM, FAA ${ }^{2,4}$ For the GEM Study Group \\ ${ }^{1}$ Tissue Pathology and Diagnostic Oncology, Royal Prince Alfred Hospital, Sydney, Australia \\ ${ }^{2}$ Melanoma Institute Australia, Sydney, Australia \\ ${ }^{3}$ Discipline of Pathology, Sydney Medical School, The University of Sydney, Sydney, Australia \\ ${ }^{4}$ School of Public Health, Sydney Medical School, The University of Sydney, Sydney, Australia \\ ${ }^{5}$ Women's College Hospital, Toronto, Canada \\ ${ }^{6}$ Department of Pathology, Memorial Sloan-Kettering Cancer Center, New York, USA \\ ${ }^{7}$ Department of Epidemiology and Biostatistics, Memorial Sloan-Kettering Cancer Center, New \\ York, USA \\ ${ }^{8}$ Murdoch Children's Research Institute, Royal Children's Hospital, Melbourne, Australia \\ ${ }^{9}$ Division of Molecular Medicine \& Genetics, University of Michigan, Ann Arbor, USA \\ ${ }^{10}$ University of Pennsylvania School of Medicine, Philadelphia, USA \\ ${ }^{11} \mathrm{CPO}$-Registro Tumori Piemonte, via San Francesco da Paola, Torino, Italy \\ ${ }^{12}$ Department of Dermatology, Lineberger Comprehensive Cancer Center, University of North \\ Carolina, Chapel Hill, North Carolina \\ ${ }^{13}$ Division of Epidemiology and Biostatistics, University of New Mexico, Albuquerque, USA
}

\section{Abstract}

Background-0.6-12.7\% of patients with primary cutaneous melanoma will develop additional melanomas. Pathologic features of tumors in patients with multiple primary cutaneous melanomas have not been well described. In this large international multi-center case-control study, we compared the clinicopathologic features of a subsequent melanoma with the preceding (usually the first) melanoma in patients with multiple primary cutaneous melanomas, and with those of melanomas in patients with single primary cutaneous melanomas.

Methods-Multiple primary melanoma (cases) and single primary invasive melanoma (controls) patients from the Genes, Environment and Melanoma (GEM) study were included if their tumors were available for pathologic review and confirmed as melanoma. Clinicopathologic

Address for correspondence: Dr. Rajmohan Murali, Human Oncology and Pathogenesis Program, Memorial Sloan-Kettering Cancer Center, 1275 York Avenue New York, NY 10065, USA, Telephone: +1 646888 3236, Facsimile: +1 646422 0890,

MuraliR@mskcc.org. 
characteristics of invasive subsequent and first melanomas in cases and invasive single melanomas in controls were compared.

Results—473 pairs comprising a subsequent and a first melanoma and 1989 single melanomas were reviewed. Forward stepwise regression modeling in 395 pairs with complete data showed that, compared to first melanomas, subsequent melanomas were: more commonly contiguous with a dysplastic nevus; more prevalent on the head/neck and legs than other sites; and thinner. Compared with single primary melanomas, subsequent melanomas were also more likely to be: associated with a contiguous dysplastic nevus; more prevalent on the head/neck and legs; and thinner. The same differences were observed when subsequent melanomas were compared with single melanomas. First melanomas were more likely than single melanomas to have associated solar elastosis and no observed mitoses.

Conclusions-Thinner subsequent than first melanomas suggest earlier diagnosis, perhaps due to closer clinical scrutiny. The association of subsequent melanomas with dysplastic nevi is consistent with the latter being risk factors or risk markers for melanoma.

\section{Keywords}

Diagnosis; Melanoma; Multiple primary melanoma; Pathology; Risk factors

\section{INTRODUCTION}

In patients with primary cutaneous melanoma (hereafter referred to as melanoma), the reported incidence of a second or higher order melanoma ranges between $0.6 \%$ and $12.7 \%{ }^{1-3}$ In patients with one melanoma, a family history of melanoma confers an increased risk for a subsequent melanoma. ${ }^{2,4-12}$ Many studies based on data from single centers, and a few based on population data, have shown that patients with non-familial melanoma also have an increased risk of developing additional melanomas. ${ }^{1-5,7-10,13-33}$ The relative risk of additional melanomas is highest in the first year after diagnosis of the first melanoma and decreases progressively with time, but is increased for at least 20 years. 1,25

Most studies of multiple melanomas have detailed the clinical and genetic characteristics of affected patients, but pathologic features of tumors in patients with MPMs have been incompletely described. To date, the pathologic features assessed have been limited to thickness and Clark level, ${ }^{8,34}$ associated dysplastic nevus, ${ }^{2,17}$ and, rarely, ulceration ${ }^{2,21}$ and regression. ${ }^{16} \mathrm{~A}$ detailed comparison of the pathologic differences between tumors in patients with multiple primary melanomas has not been reported.

In the Genes, Environment and Melanoma (GEM) Study, a large international multiinstitution case-control study, we sought to examine in detail the clinicopathologic features of melanomas in patients with multiple primary melanomas (GEM cases) and to contrast features of the subsequent melanoma with those of the preceding, usually the first, melanoma, in these patients. Furthermore, we compared the clinicopathologic features of both the subsequent and first melanoma in cases with features of the melanoma in patients with single primary melanomas (GEM controls). The aim of the study was to determine whether there were significant differences in clinicopathologic features between these groups. 


\section{METHODS}

\section{Patients and selection criteria}

The Genes, Environment and Melanoma (GEM) Study ${ }^{35}$ has investigated genetic and environmental risk factors in cutaneous melanoma patients with newly incident multiple and single primary tumors identified in eight population-based cancer registries in Australia, Canada, Italy and the United States and one hospital center estimated to cover around 50\% of the melanomas diagnosed in the state of Michigan. The GEM study is designed as a case control study in which the population at risk is survivors of a first primary melanoma. Controls were diagnosed with a first invasive primary melanoma in 2000 and cases had a newly incident second or higher order invasive or in situ melanoma in 2000-2003 and, in four centers, in 1998 and 1999 also. We used incident sampling to identify both GEM cases and GEM controls and also ascertained the preceding (usually the first) melanoma in GEM cases in local cancer registry records (average 47 months between the first and the subsequent, case-defining melanoma). Further details of the study design and its rationale have been published. ${ }^{35}$

The Study was approved by the appropriate institutional review committees and met the guidelines of the responsible governmental agencies. For the analyses in this report, GEM Study participants with single primary melanomas (controls) or multiple primary melanomas (cases) were included if their tumors were confirmed as invasive melanoma and were available for pathologic review by an experienced dermatopathologist. Patients whose tumors were entirely in situ (some subsequent melanomas in GEM cases) were excluded.

In cases, clinicopathologic characteristics of the newly incident subsequent melanoma and their preceding, usually first, melanoma were compared; we refer to these melanomas as 'subsequent' and 'first' for convenience. The order of diagnosis of the multiple melanomas could not be determined for some cases because diagnosis month and year only were obtained for the study; thus multiple melanomas with the same month of diagnosis were treated as simultaneously diagnosed and excluded from this comparison. There was a shorter time between diagnosis of the subsequent and first melanoma in cases in this analysis (mean 47 months, interquartile range (IQR) 10-72) than in all GEM cases (mean 72 months, IQR 14-110); this is probably explained by the greater difficulty of gaining access to pathology sections or slides suitable for review of first melanomas diagnosed longer ago. In separate analyses, clinicopathologic features of the subsequent and first melanomas in cases were compared with the single melanomas in controls. The clinicopathologic characteristics assessed in each melanoma are listed in Tables 1 and 2.

\section{Statistical methods}

Our primary analyses compared the clinicopathologic characteristics of subsequent and first melanomas in individual cases by estimating prevalence ratios (subsequent compared with first melanoma) using Cox regression models with equal survival times given to each subject and robust variance. This method gives unbiased effect estimates and confidence intervals and is superior to the use of logistic regression, in which odds ratio estimates of prevalence ratios are non-conservatively biased. ${ }^{36}$ Analyses were clustered on individual cases to account for within case correlation and adjusted for age at diagnosis, sex and study center. The variables 'site of melanoma' and 'presence of mitoses' were included in the multivariable models instead of the variables 'location on exposed sites' and 'mitotic rate' due to their smaller p-values in the univariate analysis. A p-value of $<0.2$ in the single variable analyses was used as a cut-off for entry into a forward stepwise multiple regression model of all clinicopathologic characteristics. The analyses comparing each of subsequent and first melanomas with single melanomas also estimated prevalence ratios in models 
adjusted for age, sex and study center but did not cluster on individual patients; a forward stepwise regression approach was again used. Only patients with valid values for all pathology variables were included in the stepwise analyses.

\section{RESULTS}

There were 3,676 patients in the GEM study population, of whom 2,470 had a single primary melanoma and 1,210 had multiple primary melanomas. Following pathology review, 1,214 (33.0\%) patients were excluded because pathology slides were not available for review, primary tumor was missing from the slides available or the review diagnosis was missing $(866,23.6 \%)$; or slide review classified the index tumor as 'not melanoma' (67, $1.8 \%)$ or 'in situ melanoma' $(281,7.6 \%)$. Totals of 473 cases with invasive multiple (subsequent and first) melanomas and 1989 controls with single melanomas were available for the analysis; 78 of the former were excluded, however, because they had the same month of diagnosis and were considered to have been diagnosed simultaneously. The age and sex distribution of the included patients (Table 1) was similar to all GEM participants. In the main GEM study, cases were generally older than GEM controls and the female/male ratio fell with age, reflecting the higher rate of increase in melanoma incidence with age in men than in women. ${ }^{35}$ More than half (58\%) of the 473 patients with multiple melanomas in this report had their most recent melanoma diagnosed within 3 years of the preceding melanoma, compared with $52 \%$ of all 1,210 GEM multiple melanoma patients.

There were a number of sizeable differences in clinicopathologic characteristics between the subsequent and first melanomas (Table 2). The subsequent melanomas were more often located on the head and neck than MPM1 (23\% vs. 16\%), though the trunk was the dominant site for both subsequent and first tumors; $50.2 \%$ of the subsequent tumors in males and $24.6 \%$ in females were on the trunk (Table 1). The subsequent melanomas were more often lentigo maligna melanoma histologic subtype (23\% vs. $14 \%$ ), though $57 \%$ of pairs were of the same histologic type, they were thinner (77\% vs. $68 \% \leq 1.0 \mathrm{~mm}$ thick), more often Clark level II (60\% vs. $48 \%$ ) or were lacking vertical growth (57\% vs. $46 \%)$. A higher proportion of subsequent than first melanomas was associated with remnants of a contiguous dysplastic nevus (24\% vs. $15 \%$ ) and more often had an associated in situ component (92\% vs. $89 \%$ ), marked solar elastosis ( $24 \%$ vs. $20 \%$ ), mitoses rated as absent (66\% vs. $63 \%$ ), and occurred on a usually exposed site ( $29 \%$ vs. $26 \%$ ). Adjusting for age at diagnosis did not produce materially different results from those in Table 2 . Generally speaking, differences between MPM2 and single primary melanoma were similar to but greater than those between MPM2 and MPM1 (Table 2).

There were no material differences between subsequent melanomas diagnosed within 1-3 months of the first melanoma (synchronous melanomas) and those diagnosed 3 months or more after it (metachronous melanomas). However, when we compared melanoma pairs with $<3$ years and $\geq 3$ years between tumours, the subsequent melanomas diagnosed in the later interval were more likely than those diagnosed in the earlier interval to be of nodular and unclassified type ( $20 \%$ vs $8 \%$ ), $>1 \mathrm{~mm}$ thick ( $31 \%$ vs $16 \%$ ), Clark level IV or V ( $46 \%$ vs $34 \%$ ) and to have mitoses (39\% vs $28 \%$ ) ( $<<0.05$ in each case; results not shown).

Apart from the higher prevalence of subsequent melanomas on the head and neck, the site distributions of subsequent and first melanomas were similar. There was a weak degree of concordance within pairs by body site (46\%; Kappa $0.22,95 \%$ CI: $0.21-0.35$; $\mathrm{p}<0.001)$.

Only a co-existing nevus, location on the head and neck or legs and less deep invasion (whether assessed by Breslow thickness, Clark level or presence of vertical growth) were identified as independently more likely to be present in subsequent melanomas than in first 
melanomas in the forward stepwise regression model (which included adjustment for age at diagnosis, sex and center, Table 3). The model fit was marginally poorer when either Clark level or Breslow thickness was substituted for vertical growth (results not shown). There were no differences between the directions of the associations of these variables with MPM2 in the multivariable model (Table 3) and those in the single variable analyses (Table 2).

Only two characteristics appeared important in a forward stepwise regression model (adjusted for age, sex and center) comparing first melanomas in multiple melanoma patients (cases) with single melanomas (controls): mitoses were present less often (prevalence ratio (PR) $0.79,95 \%$ CI 0.65-0.96) in first melanomas than in single melanomas and mild/ moderate (PR 1.43, 95\% CI 1.11-1.84) and marked solar elastosis (PR 1.41, 95\% CI 1.041.93) was present more often (results not shown). In a similar analysis comparing subsequent melanomas with single melanomas, having a contiguous dysplastic nevus (PR $1.45,95 \%$ CI 1.15-1.83), less frequent vertical growth (PR 0.79, 95\%CI 0.63-0.99) and location on the head and neck (reference category, PR 1.00) or legs (PR 1.05, 95\% CI 0.761.46) were associated more often with subsequent melanomas than single melanomas(results not shown). These results are similar to those for the comparison of subsequent and first melanomas (Table 3).

\section{DISCUSSION}

We examined many histopathologic and some clinical characteristics of multiple melanomas and found that subsequent melanomas in patients with multiple melanomas were more likely than than their first melanomas to have evidence of a contiguous dysplastic nevus, to have invaded less, and to be located on the head and neck or legs.

In studying patients with multiple melanomas, it is important to ensure that the subsequent melanomas are independent primary tumors and not cutaneous metastases from an antecedent primary melanoma. Classifying cutaneous melanomas as primary or secondary solely on histologic grounds may be challenging. ${ }^{37}$ More reliable classification is based on correlation of several clinical and pathologic features, such as location, the presence of an associated precursor/in-situ lesion, lymphatic invasion and dense lymphocytic inflammation, although both primary and metastatic melanomas may share some of these characteristics. In a recent study, Orlow and colleagues ${ }^{38}$ compared the somatic mutational profiles of pairs of melanomas designated as independent primary tumors on the basis of their clinical and pathologic characteristics. They found no significant evidence of clonal origin of the two primaries in 17 of the 19 patients examined by molecular profiling using a set of highly polymorphic genetic markers. These results suggest that most second melanomas designated clinically and pathologically as independent primary tumors are indeed independent occurrences of the disease, supporting the validity of the criteria used by experienced clinicians and pathologists in distinguishing new primaries from metastases.

Pathologic features of tumors in patients with multiple melanomas have been incompletely reported to date. Most commonly, subsequent melanomas have been reported to have invaded less than preceding melanomas, both in terms of Breslow thickness ${ }^{20-22}$ and Clark level. ${ }^{8,27}$ Studies that included in situ melanomas reported that a greater proportion of subsequent melanomas were in situ. 2, 3, 20,21, 29, 39 Although melanomas that were exclusively in situ were excluded from the present analysis, invasive subsequent melanomas were more commonly associated with an in situ component (92\%) than preceding melanomas (89\%) and single melanomas (88\%). The high prevalence of an associated in situ component supports the proposition that the subsequent melanomas in patients with multiple melanomas in this study were primary at the site of diagnosis. 
We observed a weak but significant concordance between the sites of occurrence of multiple melanoma pairs. While a significant correlation between their sites has not been reported in most studies, $8,10,14,16,20,22,40$ several studies ${ }^{19,34,39}$ did find site concordance ranging between $52 \%$ and $56 \%$. Some degree of site concordance between melanomas in the same patient would be expected because the same patterns of sun exposure and sun protection underlie the occurrence of both lesions. The comparatively weak site concordance and the fact that subsequent melanomas are diagnosed synchronously (within three months) with the first melanoma in up to $60 \%$ of patients with multiple melanomas (27\% of the 395 pairs in the present study - results not shown $)^{21}$ highlight the need for careful and complete skin examination when assessing patients with melanoma. ${ }^{39,41,42}$ Moreover, the increased risk of metachronous melanomas, the long intervals $\left(>20\right.$ years $\left.{ }^{1}\right)$ within which they may be diagnosed, and the probable benefits of early diagnosis of additional melanomas and metastatic disease suggest that patients with one melanoma may benefit from regular follow up. ${ }^{27,43}$ This suggestion is strengthened by our findings that subsequent melanomas diagnosed $\geq 3$ years after a first, when perhaps clinical follow-up has become less intense or ceased, were thicker, more likely to be of nodular type and to have mitoses, than subsequent melanomas diagnosed within 3 years of the first.

In addition to the greater site concordance of multiple melanomas, subsequent melanomas were more likely than first melanomas to be on the head and neck or legs than on the upper limbs or trunk. This too might be expected, at least for the head and neck, because of the head and neck's generally greater exposure to the sun and greater risk of melanoma per unit of surface area than other body sites, particularly in older people. ${ }^{44,45}$ This possible association of multiple melanomas with higher sun exposure is supported by the stronger association of solar elastosis with first melanomas than single melanomas in the present study, observed associations of high sun exposure ${ }^{44}$ and lack of sunscreen use $\mathrm{e}^{4}$ with an increased risk of multiple melanomas, and the finding that solar exposure at any age was associated with increased risk of developing multiple primary melanomas in the GEM study. ${ }^{46}$

Superficial spreading melanoma, lentigo maligna melanoma and nodular melanoma were, in decreasing order, the commonest histologic subtypes in each of subsequent, first and single primary melanomas in our study. Scheibner et $\mathrm{al}^{16}$ found the commonest subtypes to be superficial spreading melanoma and nodular melanoma, and that each of subsequent and first melanomas were of the same histologic type in $74 \%$ of cases, which compares with $54 \%$ in the present study. The prominence of lentigo maligna melanoma in our study probably reflects refined diagnostic criteria and better clinical recognition of this subtype of melanoma, as well as the common occurrence in Australian populations (42\% of melanomas in this analysis were from the Australian GEM center - data not shown) of high solar UV exposure, which is well known to be associated with lentigo maligna melanoma. ${ }^{47}$

Ulceration has previously been shown to be less common ${ }^{2,21}$ and regression to be more common ${ }^{16}$ in subsequent than in first melanomas. Consistently, ulceration was less common in subsequent melanomas in our study, which is in keeping with the lesser thickness of these tumors and a known correlation of ulceration with tumor thickness, ${ }^{48}$ and regression was more common, but both could have been chance differences. The difference between our findings for regression and those of Scheibner et al ${ }^{16}$ may be due to the fact that there is considerable interobserver variation in, and poor reproducibility of, the histologic assessment of regression. ${ }^{49,}, 50$

Similarly to our study, dysplastic nevi have been found to occur more frequently in patients with multiple (38-63\%) than single primary melanomas ${ }^{17,22}$ and in the general population. ${ }^{51}$ These observations suggest that dysplastic nevi are markers of risk for 
additional melanomas. They are in keeping with results of previous studies, which have shown that the presence of clinically and histologically diagnosed dysplastic nevi,, 33 a family history of dysplastic nevi, ${ }^{4}$ and classical atypical mole syndrome ${ }^{20}$ are associated with increased risk of multiple primary melanomas. Dysplastic nevi are also risk markers for the development of melanoma in melanoma-prone families. ${ }^{52-54}$ However, it is generally easier to detect a nevus remnant in thin melanomas (e.g. subsequent melanomas in patients with multiple melanomas) than in thick melanomas (e.g. first melanomas), as in the latter any residual nevus may have been overgrown by the invasive melanoma.

Differences in pathology between the paired melanomas in patients with multiple tumors, notably the reduced thickness and vertical growth in subsequent melanomas, are likely to reflect closer clinical surveillance and earlier diagnosis. Other differences, such as the more common occurrence of dysplastic nevi in association with subsequent melanomas, and the stronger association of subsequent melanomas with the most exposed body site (head and neck) are consistent with dysplastic nevi and sun exposure being risk factors or risk markers for and, in the case of dysplastic nevi, possible precursors to additional melanomas in patients with a cutaneous melanoma.

\title{
Acknowledgments
}

Sources of support: This work is supported by the following NIH/NCI grants: U01 CA83180, R01 CA112425, R01 CA112243 and R01 CA112243-05S1. Professor Scolyer is a Cancer Institute New South Wales Clinical Research Fellow.

\begin{abstract}
The study was conducted by the GEM Study Group: Marianne Berwick (PI, University of New Mexico), Memorial Sloan-Kettering Cancer Center, New York, NY, USA: Colin Begg (Co-PI), Irene Orlow (Co-Investigator), Urvi Mujumdar (Project Coordinator), Klaus Busam (Dermatopathologist), Pampa Roy (Laboratory Technician). Study Centers: The University of Sydney and The Cancer Council New South Wales, Sydney (Australia): Bruce Armstrong (PI), Anne Kricker (co-PI), Melisa Litchfield (Study Coordinator). Menzies Research Institute, University of Tasmania, Hobart (Australia): Terence Dwyer (PI, currently at the Murdoch Childrens Research Institute, Melbourne, Victoria), Paul Tucker (Dermatopathologist), Alison Venn (co-Investigator), Nicola Stephens (Study Coordinator). British Columbia Cancer Agency, Vancouver (Canada): Richard Gallagher (PI), Teresa Switzer (Coordinator). Cancer Care Ontario, Toronto (Canada): Loraine Marrett (PI), Elizabeth Theis (CoInvestigator), Lynn From (Dermatopathologist), Noori Chowdhury (Coordinator), Louise Vanasse (Coordinator). Centro per la Prevenzione Oncologia Torino, Piemonte (Italy): Stefano Rosso (PI), Roberto Zanetti (co-PI), Carlotta Sacerdote (Coordinator). University of California, Irvine (USA): Hoda Anton-Culver (PI), Nancy Leighton (Coordinator). University of Michigan, Ann Arbor (USA): Stephen Gruber (PI), Joanne Jeter (Coordinator). New Jersey Department of Health and Senior Services, Trenton (USA): Judith Klotz (PI), Homer Wilcox (Co-PI), Helen Weiss (Coordinator). University of North Carolina, Chapel Hill (USA): Robert Millikan (PI), Nancy Thomas (CoInvestigator), Dianne Mattingly (Coordinator), Jon Player (Laboratory Technician). University of Pennsylvania, Philadelphia, PA (USA): Timothy Rebbeck (PI), Peter Kanetsky (Co-Investigator), Amy Walker (Laboratory Manager), Saarene Panossian (Laboratory Technician). Consultants: Julia Lee Taylor and Sasha Madronich, National Centre for Atmospheric Research, Boulder, Colorado (USA).
\end{abstract}

\section{References}

1. Savoia P, Quaglino P, Verrone A, et al. Multiple primary melanomas: analysis of 49 cases. Melanoma Res. 1998; 8(4):361-6. [PubMed: 9764812]

2. Ferrone CR, Ben Porat L, Panageas KS, et al. Clinicopathological features of and risk factors for multiple primary melanomas. JAMA. 2005; 294(13):1647-54. [PubMed: 16204664]

3. Uliasz A, Lebwohl M. Patient education and regular surveillance results in earlier diagnosis of second primary melanoma. Int J Dermatol. 2007; 46(6):575-7. [PubMed: 17550554]

4. Burden AD, Newell J, Andrew N, et al. Genetic and environmental influences in the development of multiple primary melanoma. Arch Dermatol. 1999; 135(3):261-5. [PubMed: 10086446]

5. Burden AD, Vestey JP, Sirel JM, et al. Multiple primary melanoma: risk factors and prognostic implications. BMJ. 1994; 309(6951):375. [PubMed: 8081136]

6. Lucchina LC, Barnhill RL, Duke DM, et al. Familial cutaneous melanoma. Melanoma Res. 1995; 5(6):413-8. [PubMed: 8589615] 
7. Gupta BK, Piedmonte MR, Karakousis CP. Attributes and survival patterns of multiple primary cutaneous malignant melanoma. Cancer. 1991; 67(7):1984-9. [PubMed: 2004315]

8. Moseley HS, Giuliano AE, Storm FK 3rd, et al. Multiple primary melanoma. Cancer. 1979; 43(3): 939-44. [PubMed: 427733]

9. Slingluff CL Jr, Vollmer RT, Seigler HF. Multiple primary melanoma: incidence and risk factors in 283 patients. Surgery. 1993; 113(3):330-9. [PubMed: 8441968]

10. Kang S, Barnhill RL, Mihm MC Jr, et al. Multiple primary cutaneous melanomas. Cancer. 1992; 70(7):1911-6. [PubMed: 1525766]

11. Reimer RR, Clark WH Jr, Greene MH, et al. Precursor lesions in familial melanoma. A new genetic preneoplastic syndrome. JAMA. 1978; 239(8):744-6. [PubMed: 621895]

12. Frank W, Rogers GS. Melanoma update. Second primary melanoma. J Dermatol Surg Oncol. 1993; 19(5):427-30. [PubMed: 8496486]

13. Pack GT, Scharnagel IM, Hillyer RA. Multiple primary melanoma. Cancer. 1952; 5(6):1110-5. [PubMed: 12998017]

14. Beardmore GL, Davis NC. Multiple primary cutaneous melanomas. Arch Dermatol. 1975; 111(5): 603-9. [PubMed: 1130805]

15. Cascinelli N, Fontana V, Cataldo I, et al. Multiple primary melanoma. Tumori. 1975; 61(5):481-6. [PubMed: 1209747]

16. Scheibner A, Milton GW, McCarthy WH, et al. Multiple primary melanoma - a review of 90 cases. Australas J Dermatol. 1982; 23(1):1-8. [PubMed: 7126070]

17. Titus-Ernstoff L, Duray PH, Ernstoff MS, et al. Dysplastic nevi in association with multiple primary melanoma. Cancer Res. 1988; 48(4):1016-8. [PubMed: 3338073]

18. Ariyan S, Poo WJ, Bolognia J, et al. Multiple primary melanomas: data and significance. Plast Reconstr Surg. 1995; 96(6):1384-9. [PubMed: 7480238]

19. Giles G, Staples M, McCredie M, et al. Multiple primary melanomas: an analysis of cancer registry data from Victoria and New South Wales. Melanoma Res. 1995; 5(6):433-8. [PubMed: 8589618]

20. Marghoob AA, Slade J, Kopf AW, et al. Risk of developing multiple primary cutaneous melanomas in patients with the classic atypical-mole syndrome: a case-control study. Br J Dermatol. 1996; 135(5):704-11. [PubMed: 8977668]

21. Brobeil A, Rapaport D, Wells K, et al. Multiple primary melanomas: implications for screening and follow-up programs for melanoma. Ann Surg Oncol. 1997; 4(1):19-23. [PubMed: 8985513]

22. Johnson TM, Hamilton T, Lowe L. Multiple primary melanomas. J Am Acad Dermatol. 1998; 39(3):422-7. [PubMed: 9738776]

23. Monzon J, Liu L, Brill H, et al. CDKN2A mutations in multiple primary melanomas. N Engl J Med. 1998; 338(13):879-87. [PubMed: 9516223]

24. Bhatia S, Estrada-Batres L, Maryon T, et al. Second primary tumors in patients with cutaneous malignant melanoma. Cancer. 1999; 86(10):2014-20. [PubMed: 10570426]

25. DiFronzo LA, Wanek LA, Elashoff R, et al. Increased incidence of second primary melanoma in patients with a previous cutaneous melanoma. Ann Surg Oncol. 1999; 6(7):705-11. [PubMed: 10560858]

26. Wolff J, Wollina U. Second malignancies in melanoma patients in Thuringia. J Eur Acad Dermatol Venereol. 2000; 14(6):479-83. [PubMed: 11444270]

27. DiFronzo LA, Wanek LA, Morton DL. Earlier diagnosis of second primary melanoma confirms the benefits of patient education and routine postoperative follow-up. Cancer. 2001; 91(8):1520-4. [PubMed: 11301400]

28. Schmid-Wendtner MH, Baumert J, Wendtner CM, et al. Risk of second primary malignancies in patients with cutaneous melanoma. Br J Dermatol. 2001; 145(6):981-5. [PubMed: 11899153]

29. Stam-Posthuma JJ, van Duinen C, Scheffer E, et al. Multiple primary melanomas. J Am Acad Dermatol. 2001; 44(1):22-7. [PubMed: 11148472]

30. Blackwood MA, Holmes R, Synnestvedt M, et al. Multiple primary melanoma revisited. Cancer. 2002; 94(8):2248-55. [PubMed: 12001124]

31. Doubrovsky A, Menzies SW. Enhanced survival in patients with multiple primary melanoma. Arch Dermatol. 2003; 139(8):1013-8. [PubMed: 12925389] 
32. Goggins WB, Tsao H. A population-based analysis of risk factors for a second primary cutaneous melanoma among melanoma survivors. Cancer. 2003; 97(3):639-43. [PubMed: 12548605]

33. Titus-Ernstoff L, Perry AE, Spencer SK, et al. Multiple primary melanoma: two-year results from a population-based study. Arch Dermatol. 2006; 142(4):433-8. [PubMed: 16618861]

34. Bower MR, Scoggins CR, Martin RC 2nd, et al. Second primary melanomas: incidence and outcome. American Surgeon. 2010; 76(7):675-81. [PubMed: 20698369]

35. Begg CB, Hummer AJ, Mujumdar U, et al. A design for cancer case-control studies using only incident cases: experience with the GEM study of melanoma. Int J Epidemiol. 2006; 35(3):75664. [PubMed: 16556646]

36. Barros AJ, Hirakata VN. Alternatives for logistic regression in cross-sectional studies: an empirical comparison of models that directly estimate the prevalence ratio. BMC Med Res Methodol. 2003; 3:21. [PubMed: 14567763]

37. Guerriere-Kovach PM, Hunt EL, Patterson JW, et al. Primary melanoma of the skin and cutaneous melanomatous metastases: comparative histologic features and immunophenotypes. Am J Clin Pathol. 2004; 122(1):70-7. [PubMed: 15272532]

38. Orlow I, Tommasi DV, Bloom B, et al. Evaluation of the clonal origin of multiple primary melanomas using molecular profiling. J Invest Dermatol. 2009; 129(8):1972-82. [PubMed: 19282844]

39. Manganoni AM, Farisoglio C, Tucci G, et al. The importance of self-examination in the earliest diagnosis of multiple primary cutaneous melanomas: a report of 47 cases. J Eur Acad Dermatol Venereol. 2007; 21(10):1333-6. [PubMed: 17958838]

40. Allen AC, Spitz S. Malignant melanoma; a clinicopathological analysis of the criteria for diagnosis and prognosis. Cancer. 1953; 6(1):1-45. [PubMed: 13009650]

41. Rigel DS, Friedman RJ, Kopf AW, et al. Importance of complete cutaneous examination for the detection of malignant melanoma. J Am Acad Dermatol. 1986; 14(5 Pt 1):857-60. [PubMed: 3711396]

42. Carli P, De Giorgi V, Chiarugi A, et al. Multiple synchronous cutaneous melanomas: implications for prevention. Int J Dermatol. 2002; 41(9):583-5. [PubMed: 12358828]

43. Poo-Hwu WJ, Ariyan S, Lamb L, et al. Follow-up recommendations for patients with American Joint Committee on Cancer Stages I-III malignant melanoma. Cancer. 1999; 86(11):2252-8. [PubMed: 10590365]

44. Green A, MacLennan R, Youl P, et al. Site distribution of cutaneous melanoma in Queensland. Int J Cancer. 1993; 53(2):232-6. [PubMed: 8425760]

45. Whiteman DC, Bray CA, Siskind V, et al. A comparison of the anatomic distribution of cutaneous melanoma in two populations with different levels of sunlight: the west of Scotland and Queensland, Australia 1982-2001. Cancer Causes Control. 2007; 18(5):485-91. [PubMed: 17450418]

46. Kricker A, Armstrong BK, Goumas C, et al. Ambient UV, personal sun exposure and risk of multiple primary melanomas. Cancer Causes Control. 2007; 18(3):295-304. [PubMed: 17206532]

47. Duncan LM. The classification of cutaneous melanoma. Hematol Oncol Clin North Am. 2009; 23(3):501-13. ix. [PubMed: 19464599]

48. Balch CM, Wilkerson JA, Murad TM, et al. The prognostic significance of ulceration of cutaneous melanoma. Cancer. 1980; 45(12):3012-7. [PubMed: 7388745]

49. Lock-Andersen J, Hou-Jensen K, Hansen JP, et al. Observer variation in histological classification of cutaneous malignant melanoma. Scand J Plast Reconstr Surg Hand Surg. 1995; 29(2):141-8. [PubMed: 7569811]

50. Corona R, Mele A, Amini M, et al. Interobserver variability on the histopathologic diagnosis of cutaneous melanoma and other pigmented skin lesions. J Clin Oncol. 1996; 14(4):1218-23. [PubMed: 8648377]

51. Crutcher WA, Sagebiel RW. Prevalence of dysplastic naevi in a community practice. Lancet. 1984; 1(8379):729. [PubMed: 6143053]

52. Greene MH, Clark WH Jr, Tucker MA, et al. High risk of malignant melanoma in melanoma-prone families with dysplastic nevi. Ann Intern Med. 1985; 102(4):458-65. [PubMed: 3977193] 
53. Tucker MA, Fraser MC, Goldstein AM, et al. Risk of melanoma and other cancers in melanomaprone families. J Invest Dermatol. 1993; 100(3):350S-355S. [PubMed: 8440923]

54. Carey WP Jr, Thompson CJ, Synnestvedt M, et al. Dysplastic nevi as a melanoma risk factor in patients with familial melanoma. Cancer. 1994; 74(12):3118-25. [PubMed: 7982177] 


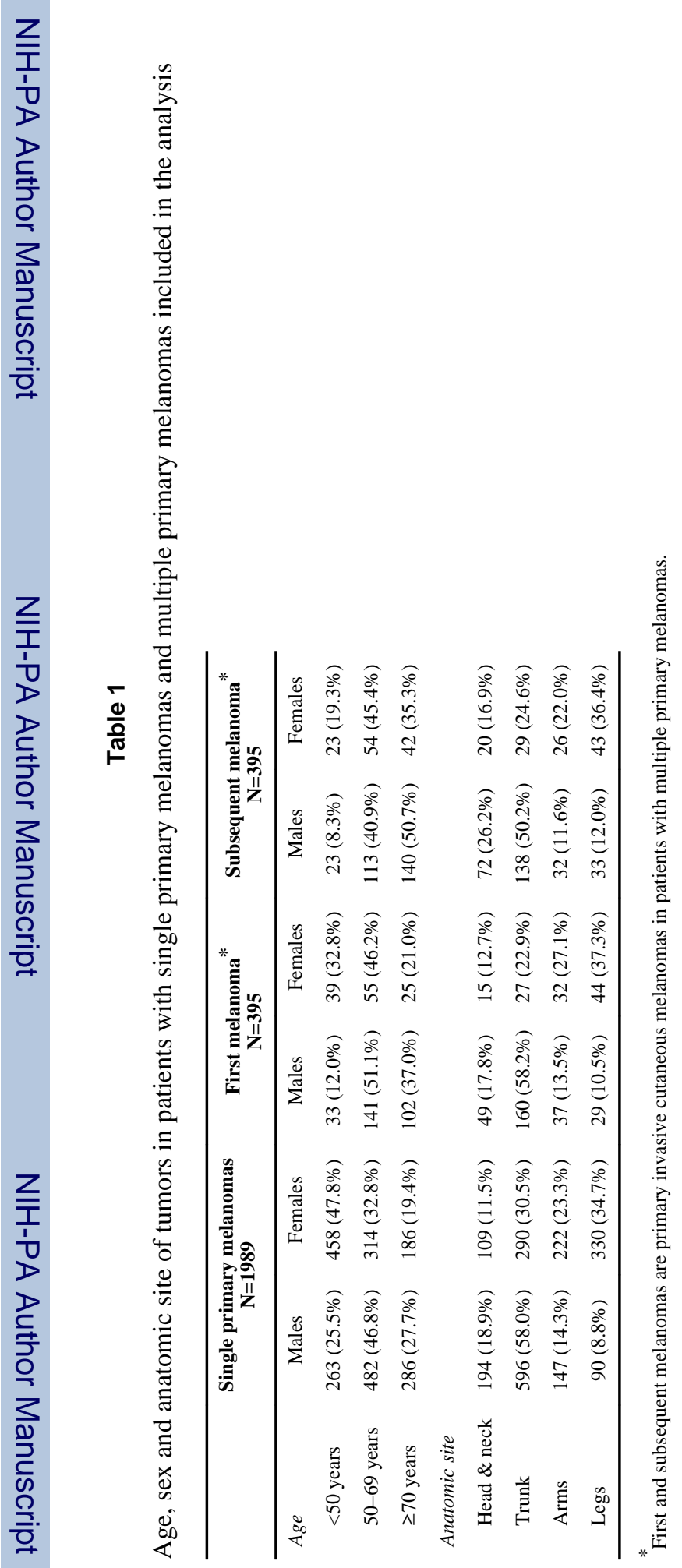




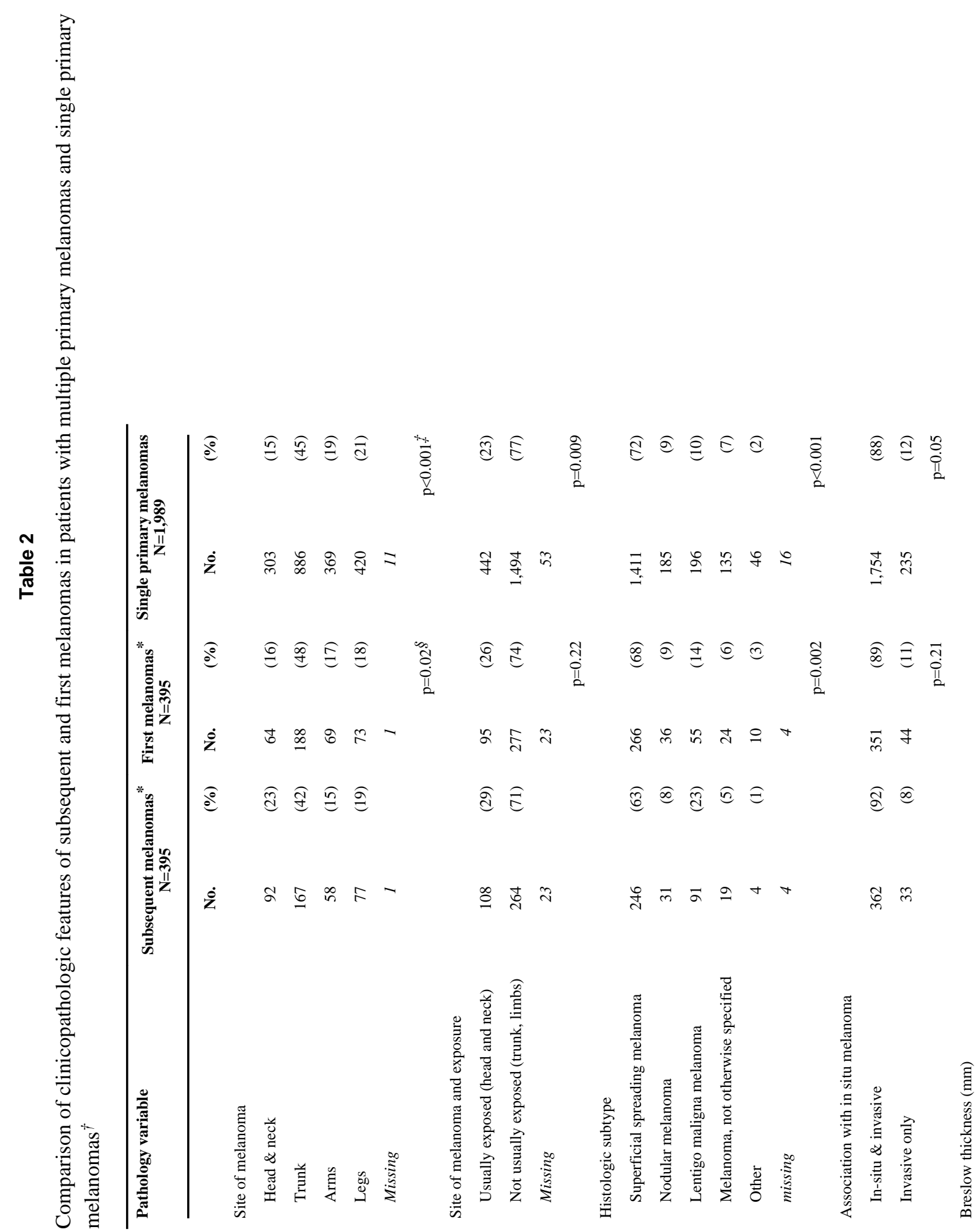


Murali et al.

Page 13

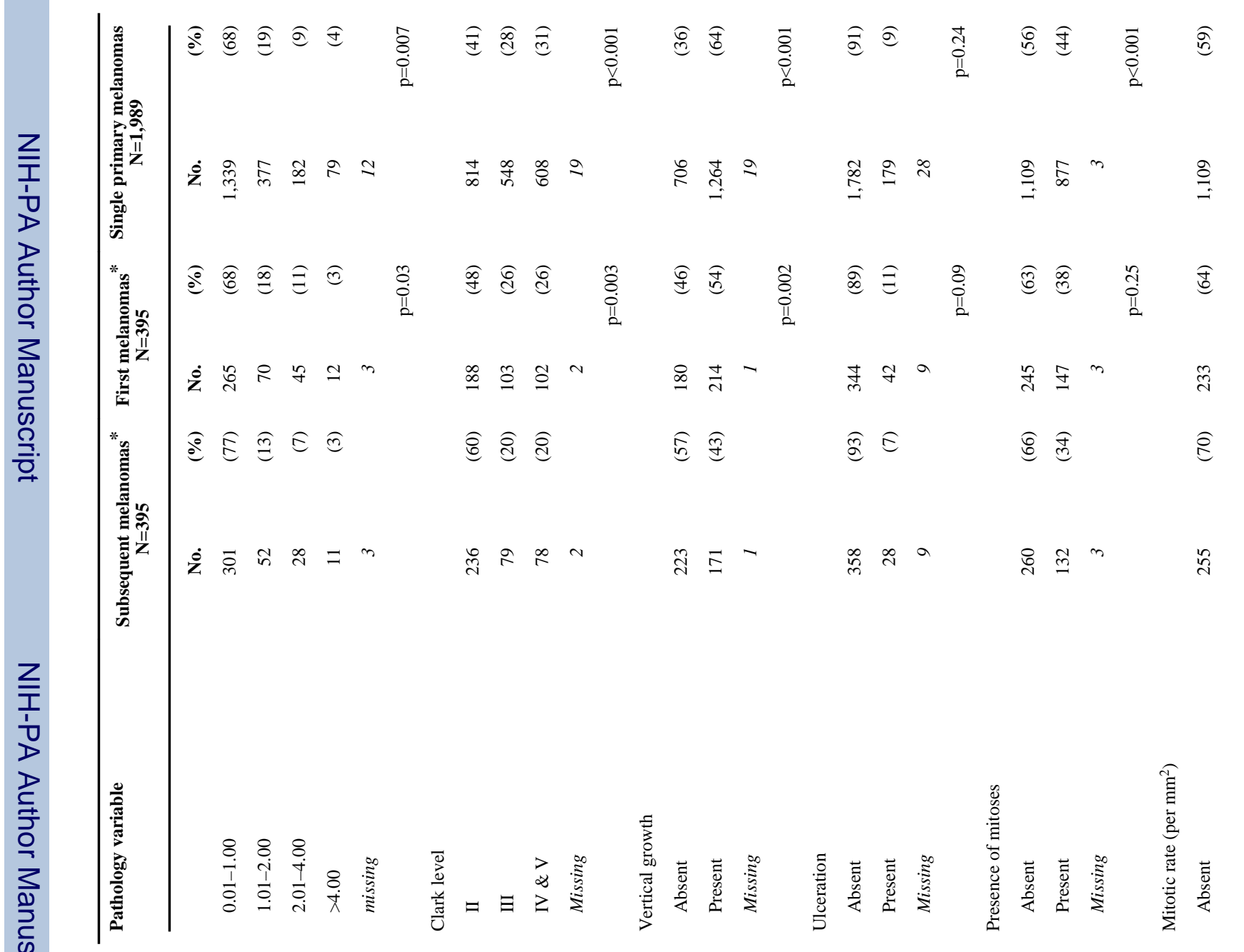




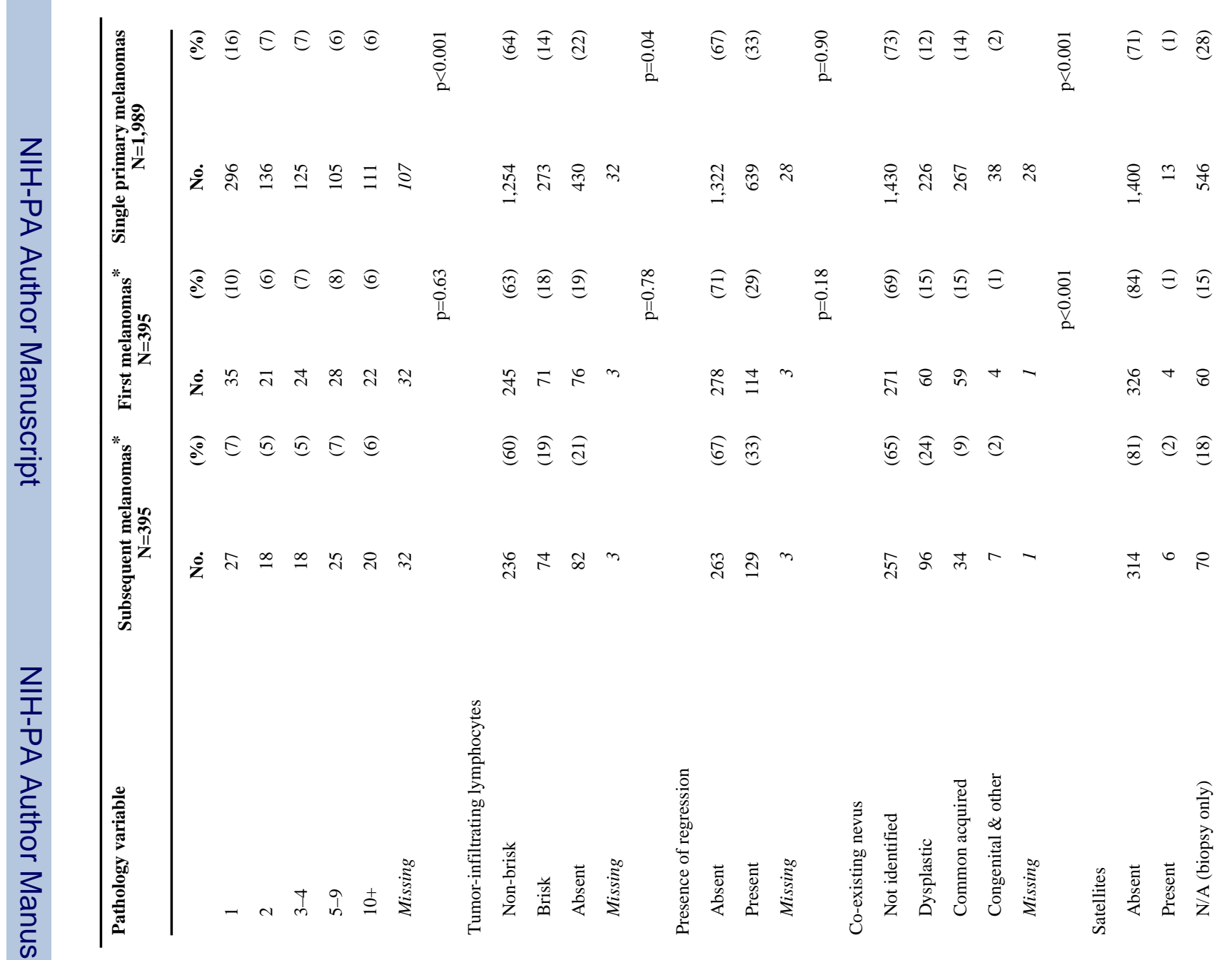


Murali et al.

Page 15

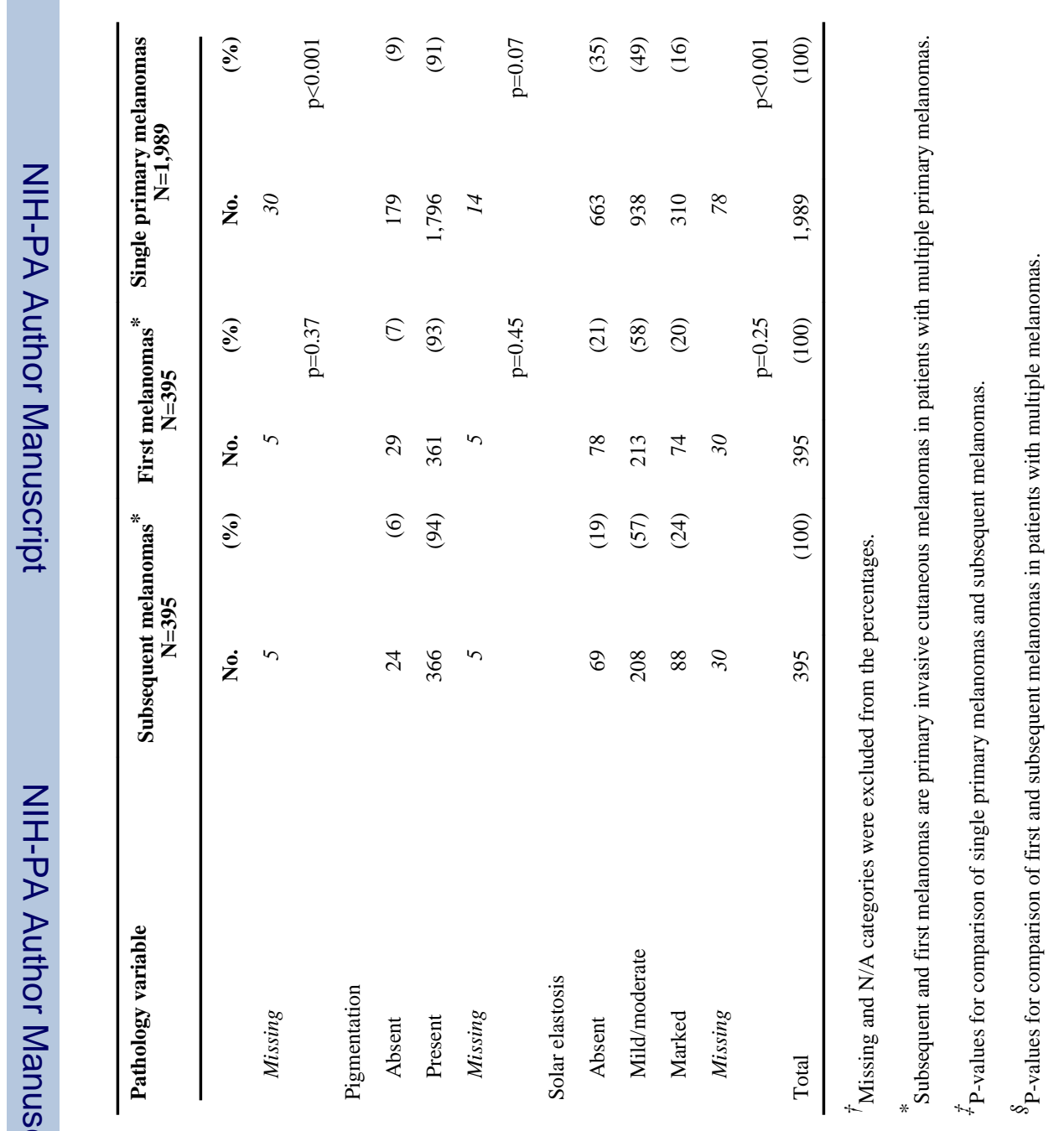

훔

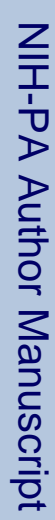

Ann Surg Oncol. Author manuscript; available in PMC 2013 March 1. 
Table 3

Results of a stepwise multiple regression analysis to identify variables that independently distinguished subsequent from first melanomas in patients with multiple primary melanomas

\begin{tabular}{|c|c|c|c|c|}
\hline \multirow[t]{2}{*}{ Pathology variables } & \multicolumn{2}{|c|}{ Tumor } & \multirow[t]{2}{*}{ Prevalence ratios $^{\dagger}(95 \%$ CI) for MPM2 } & \multirow[t]{2}{*}{ p-value } \\
\hline & First melanoma* & Subsequent melanoma* & & \\
\hline Co-existing nevus & & & & $<0.001$ \\
\hline Not identified & 226 & 227 & 1.0 & \\
\hline Dysplastic & 54 & 83 & $1.29(1.10-1.53)$ & \\
\hline Common acquired & 54 & 22 & $0.61(0.43-0.87)$ & \\
\hline Congenital \& other & 2 & 4 & $1.78(0.97-3.29)$ & \\
\hline Vertical growth & & & & 0.01 \\
\hline Absent & 157 & 191 & 1.0 & \\
\hline Present & 179 & 145 & $0.82(0.70-0.95)$ & \\
\hline Site of melanoma & & & & 0.04 \\
\hline Head \& neck & 56 & 78 & 1.0 & \\
\hline Trunk & 156 & 143 & $0.81(0.68-0.96)$ & \\
\hline Arms & 61 & 48 & $0.78(0.60-1.02)$ & \\
\hline Legs & 63 & 67 & $0.98(0.81-1.19)$ & \\
\hline
\end{tabular}

First and subsequent melanomas are primary invasive cutaneous melanomas in patients with multiple primary melanomas.

${ }^{\dagger}$ Prevalence ratio for subsequent melanoma compared with first melanoma in patients with multiple primary melanomas, clustered on patient and adjusted for age at diagnosis of lesion, sex, GEM center and all other variables in table. Highest p-value for entry $0.2 ; 336$ cases with complete data for all variables included in the analysis. 